\title{
PERANCANGAN SISTEM INFORMASI COMPANY PROFILE MENGGUNAKAN ADOBE FLASH CS5 PADA SMA SWASTA KARYA SEDAR BIRU-BIRU
}

\author{
Ayu Wulandari, Dedi Wahyudi, Husni Mubarak \\ Alumni Sekolah Tinggi Ilmu Manajemen Sukma \\ Program studi Manajemen, Sekolah Tinggi Ilmu Manajemen \\ Dediw7084@gmail.com, Husnimubarak0707@gmail.com
}

\begin{abstract}
The purpose of this research is to build a company profile to $b$ used as a media campaign to the public and inform about the general picture of the school, especially in the development of facilities and facilities of the school Private High School Karya Sedar BiruBiru. Data analysis using Adobe Flash CS5. Result of research indicate that with company profile done by using Adobe Flash CS5 can produce display of animation content in the unity animation movement and company profile can use as media in publish and inform profile at Private High School Karya Sedar Biru-Biru.
\end{abstract}

Keyword: Information System, Company Profile, Adobe Flash CS5.

\section{PENDAHULUAN}

SMA Swasta Karya Sedar merupakan salah satu institusi pendidikan yang ada di kabupaten Deli Serdang tepatnya di kecamatan Biru-Biru. SMA Swasta Karya Sedar resmi memiliki nomor induk sekolah (NIS) 300500, NSS 3040701067 dan izin operasional yaitu: SK Kadis Pendidikan dan Pengajaran Kabupaten Deli Serdang Nomor:421/2101/PDM/2010. SMA Swasta Karya Sedar Biru-Biru adalah salah satu institusi pendidikan yang belum memiliki fasilitas company profile untuk memberikan informasi kepada warga sekolah maupun masyarakat luas. Seiring dengan berkembangnya SMA Swasta Karya Sedar BiruBiru sebagai salah satu SMA yang menghasilkan sumber daya manusia, maka berbagai fasilitas sarana dan prasarana yang mendukung untuk terlaksananya proses pembelajaran yang baik yang berkualitas kini terus dilakukan dalam menunjang kebutuhan perkembangan dan kemajuan dibidang ilmu pengetahuan dan teknologi.

Yulianna (2013) dalam penelitiannya, bahwa dengan adanya video profile SMA 2 Surakarta maka pihak sekolah dapat memberikan penjelasan tentang situasi dan keadaan sekolah melalui media digital dan dapat mempromosikan sekolah kepada masyarakat. Penelitian lain dilakukan oleh Purnomo (2013) hasil penelitian ini adalah dengan adanya profil perusahaan tersebut, maka perusahaan dapat melakukan promosi yang lebih luas.

\section{Perumusan Masalah}

Berdasarkan uraian diatas, maka penulis merumuskan masalah sebagai berikut: Bagaimana merancang Sistem Informasi Company Profile menggunakan Adobe Flash CS5 Pada SMA Swasta Karya Sedar Biru-Biru?

\section{Batasan Masalah}

Untuk memperjelas arah penelitian skripsi ini, maka penulis membatasi masalah hanya pada perancangan Sistem Informasi Company Profile menggunakan Adobe Flash CS5 Pada SMA Swasta Karya Sedar Biru-Biru. 


\section{Tujuan Penelitian}

Tujuan dari penyusunan skripsi ini adalah membangun Company Profile untuk digunakan sebagai media promosi kepada masyarakat luas dan menginformasikan tentang gambaran umum sekolah, khususnya dalam perkembangan fasilitas dan sarana sekolah pada SMA Swasta Karya Sedar Biru-Biru.

\section{METODE PENELITIAN}

\section{Metode Pengumpulan Data}

Metode pengumpulan data merupakan langkah yang paling strategis dalam penelitian, karena tujuan utama darai penelitian adalah memperoleh data. Dalam penelitian ini metode pengumpulan data yang digunakan penulis adalah:

1. Observasi (peninjauan secara langsung)

Observasi adalah pengumpulan data yang diperoleh berdasarkan pengamatan secara langsung dengan mengunjungi dan mengamati langsung terhadap kegiatan yang sedang berjalan di SMA Swasta Karya Sedar Biru-Biru.

2. Wawancara

Wawancara adalah pengambilan data yang dilakukan dengan cara melakukan tanya jawab secara langsung sambil bertatap muka antara pewawancara terhadap responden guna memperoleh keterangan untuk melengkapi data yang ada hubungannya dengan penelitian.

3. Kepustakaan

Metode dengan cara ini dimaksudkan untuk memberikan landasan-landasan yang kuat dengan membaca atau membahas buku-buku yang berhubungan dengan permasalahan.

\section{Metode Analisis Data}

Microsoft windows menjadi pilihan penulis dalam pembuatan sistem aplikasi ini, karena merupakan sistem operasi komputer yang sangat lazim digunakan orang untuk saat ini. Tidak cukup dengan sistem operasi Microsoft

Windows saja untuk membuat sistem aplikasi ini, tetapi ada software yang mendukungnya, yaitu:

\section{Adobe Flash CS5}

Adobe Flash CS5 adalah salah satu perangkatlunak computer yang merupakan produk unggulan Adobe Systems. Adobe Flash CS5 merupakan aplikasi yang digunakan untuk melakukan desain dan membangun perangkat presentasi, publikasi atau aplikasi lainya yang membutuhkan ketersediaan sarana interaksi dengan penggunanya. Proyek yang dibangun dengan Flash terdiri atas teks, gambar, animasi, sound, video serta efek-efek khusus lainnya. Adobe Flash CS5 sering digunakan untuk membuat gambar yang didesain khusus untuk pembuatan animasi.

Adobe Flash CS5 merupakan aplikasi dengan berbagai kelebihan. Adobe Flash CS5 didesain dengan kemampuan untuk membuat animasi dua dimensi berbasis vector yang canggih dan paling popular, sehingga banyak digunakan oleh para animator dunia untuk membuat suatu tampilan animasi interaktif. Beberapa factor yang mendukung kepopuleran Flash sebagai suatu aplikasi untuk keperluan desain dan pembuatan animasi antara lain adalah memiliki format grafis berbasis vector, kapasitas file hasil yang kecil, memiliki kemampuan tinggi dalam mengatur interativitas program, memiliki kelengkapan fasilitas dalam melakukan desain dan lain sebagainya. 


\section{HASIL DAN PEMBAHASAN}

\section{Pembahasan}

Untuk mengoperasikan sistem informasi company profile ini, diperlukan adanya implementasi terhadap sistem. Implementasi sistem adalah proses penerapansistem ke dalam suatu program aplikasi komputer.

\section{Tampilan Menu Home}

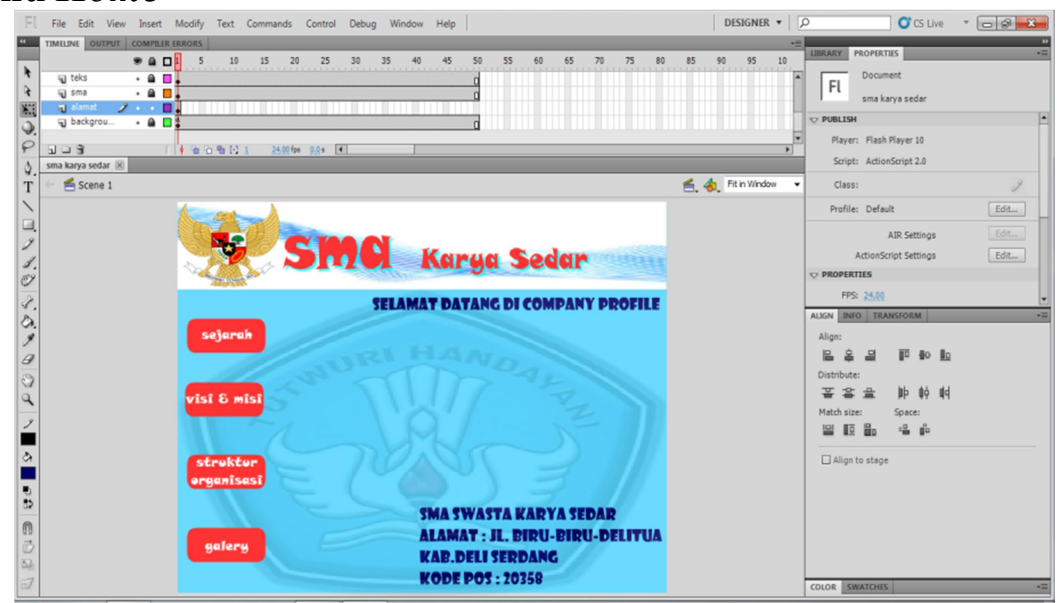

Gambar 1 Tampilan Menu Home

Pada tampilan ini, ada konten yang berisi ucapan selamat datang pada company profile SMA Swasta Karya Sedar Biru-Biru.

\section{Tampilan Menu Sejarah}

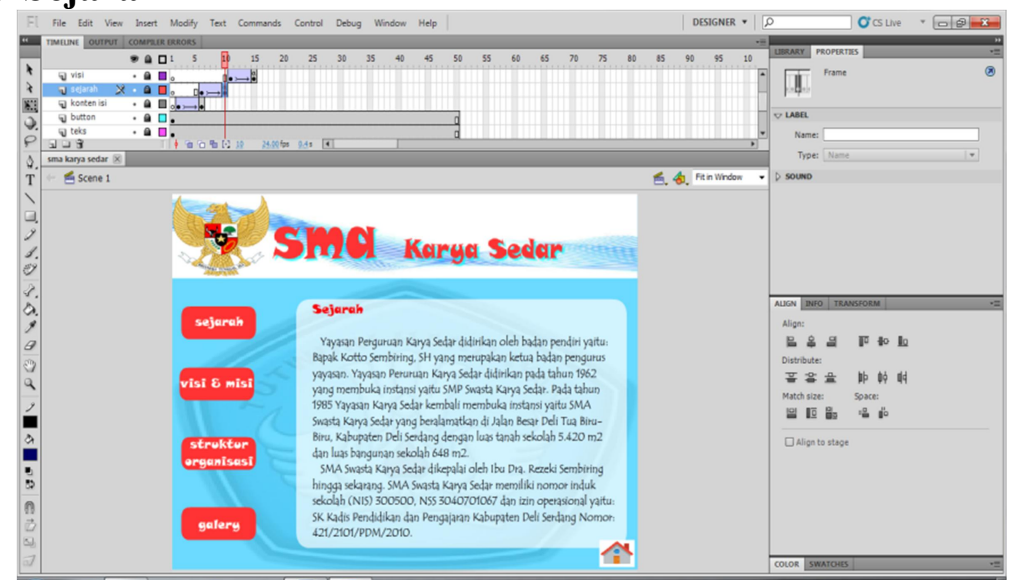

Gambar 2 Tampilan Menu Sejarah

Pada tampilan menu sejarah, ketika button sejarah di klik maka akan menampilkan konten yang berisi sejarah dari SMA Karya Sedar Biru-Biru. 


\section{Tampilan Menu Visi dan Misi}

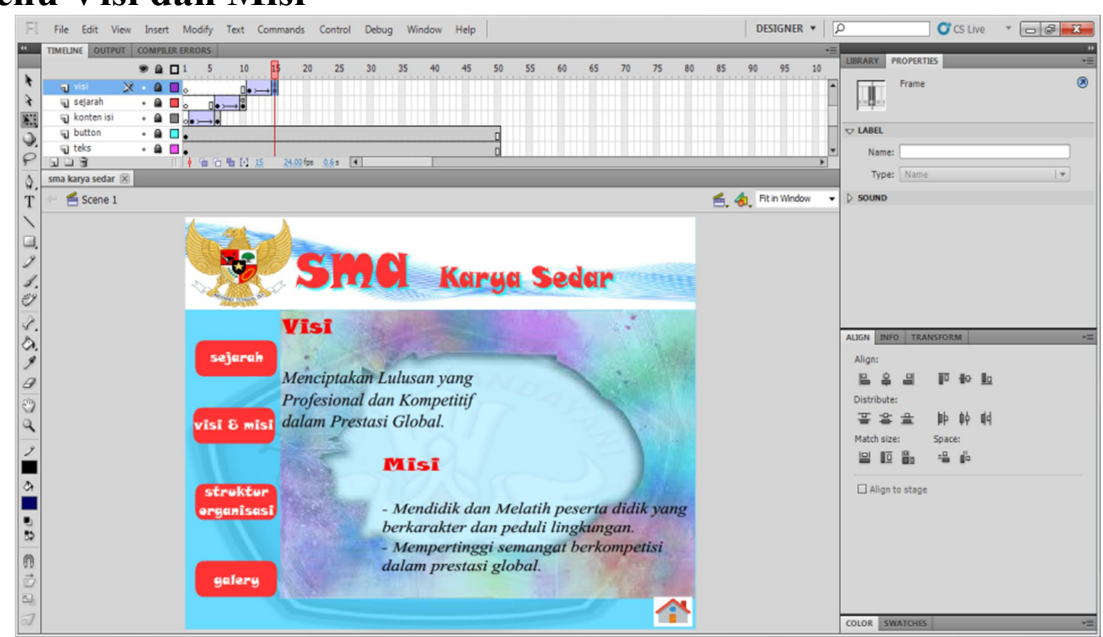

Gambar 3. Tampilan Menu Visi dan Misi

Pada tampilan menu visi dan misi, ketika button visi dan misi di klik maka akan menampilkan konten yang berisi visi dan misi dari SMA Karya Sedar Biru-Biru.

\section{Tampilan Menu Struktur Organisasi}

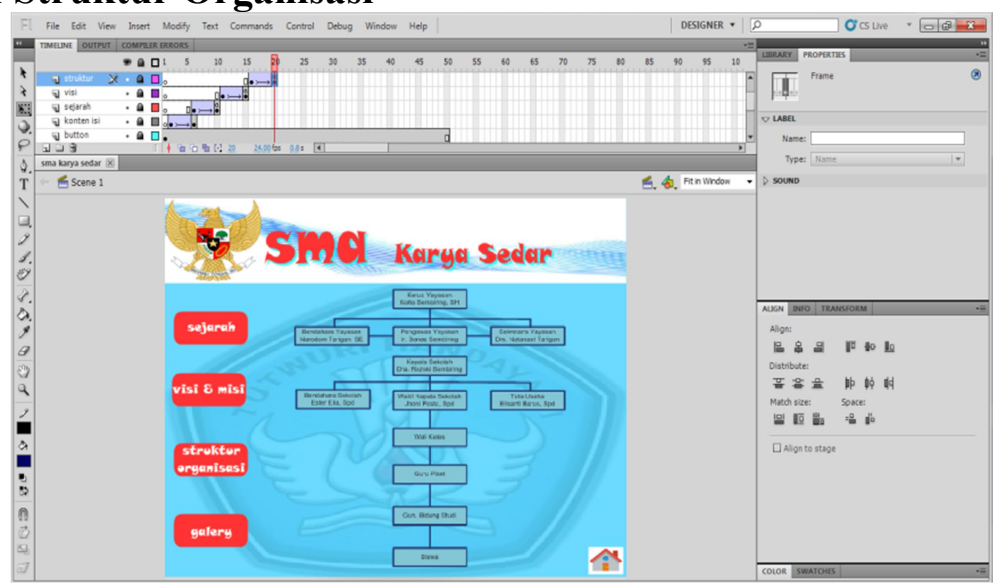

Gambar 4. Tampilan Menu Struktur Organisasi

Pada tampilan menu struktur organisasi, ketika button struktur organisasi di klik maka akan menampilkan struktur organisasi dari SMA Karya Sedar Biru-Biru.

\section{Tampilan Menu Galery}

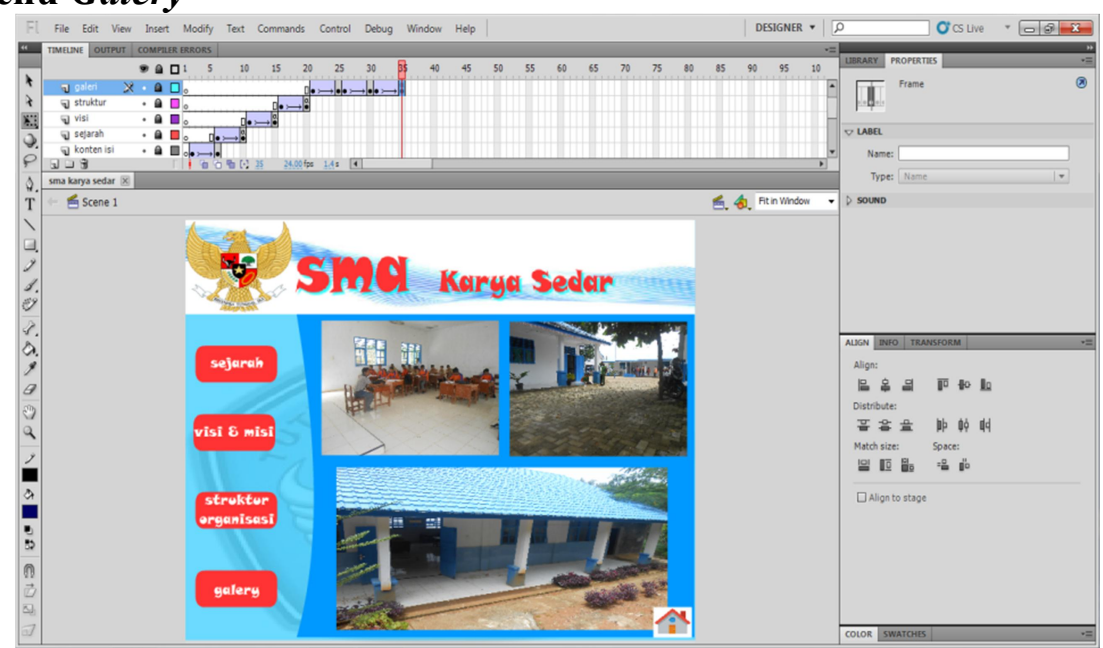

Gambar 5 Tampilan Menu Galery 
Pada tampilan menu galery, ketika button gallery di klik maka akan menampilkan gambar dari lingkungan SMA Swasta Karya Sedar Biru-Biru.

\section{Jenis Format File}

Dalam proses pembuatan Company Profile dari SMA Swasta Karya Sedar Biru-Biru, jenis format file yang digunakan dalam mempublikasikan animasi yang telah dibuat yaitu file exe. Mempublikasikan animasi, berarti mengkonversi animasi yang telah selesai dibuat menjadi file tunggal yang siap ditampilkan atau dipresentasikan. Perintah publish yang terdapat di Adobe Flash CS5 akan mempublikasikan animasi ke dalam format file exe. Berikut adalah format animasi company profile sekolah tersebut.

\section{Format File Exe}

Format file exe merupakan jenis file komputer yang di akhir dengan ekstensi "exe" atau dikenal sebagai file eksekusi (executable file). Ketika file exe di klik, maka secara otomatis komputer akan mengeksekusi file exe tersebut. File exe hanyalah salah satu dari beberapa jenis format file yang diakui oleh berbagai macam sistem operasi komputer. Berikut adalah format file exe animasi company profile SMA Swasta Karya Sedar Biru-Biru.

\section{Gambar 4.6. Format File Exe}

Pada gambar diatas, menunjukkan format file exe animasi company profile SMA Swasta Karya Sedar Biru-Biru yang dipublikasikan dengan menggunakan Adobe Flash CS5. Format file exe dapat digunakan untuk mempersentasikan animasi tanpa bantuan program lain. Format file exe dapat disebarluaskan kepada seluruh lapisan masyarakat dengan menggunakan perangkat komputer, seperti CD (Compact Disk), flashdisk dan lain sebagainya. Format file exe yang telah selesai dibuat dapat digunakan untuk menginformasikan tentang profile SMA Swasta Karya Sedar Biru-Biru.

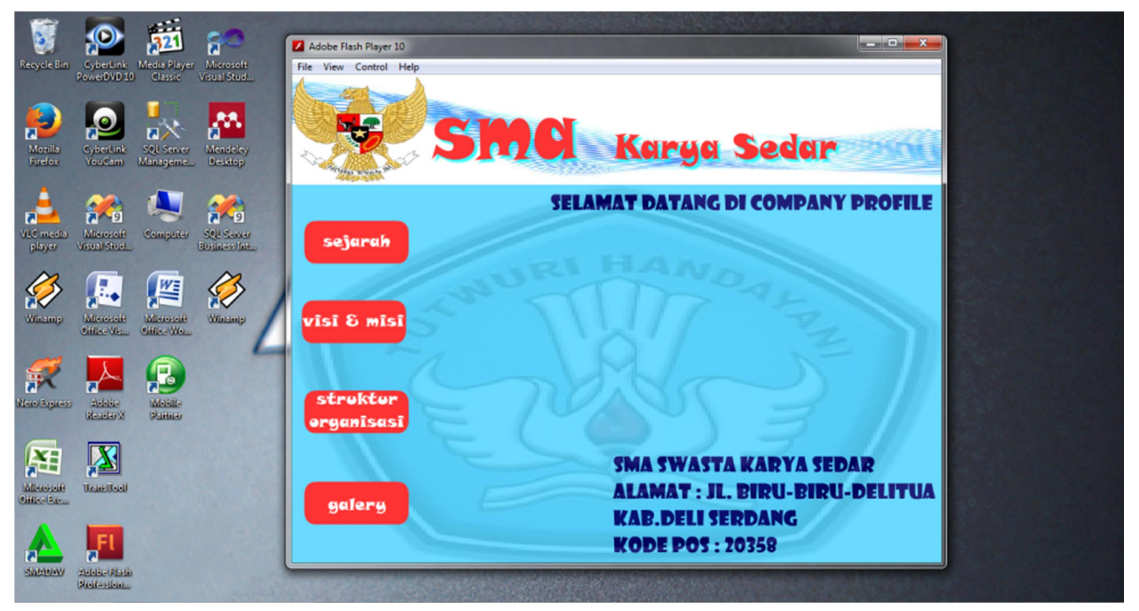

\section{Kesimpulan}

1. Pembuatan Company Profile dilakukan dengan menggunakan Adobe Flash CS5, sehingga menghasilkan tampilan konten animasi berupa gambar dan teks dalam kesatuan pergerakan animasi.

Tampilan Company Profile dapat digunakan sebagai media dalam mempublikasikan dan menginformasikan profil SMA Swasta Karya Sedar Biru-Biru kepada seluruh lapisan masyarakat. 


\section{REFERENCES}

Batubara, A., \& Hidayat, R. (2016). Pengaruh Penetapan Harga dan Promosi terhadap Tingkat Penjualan Tiket pada PSA Mihin Lanka Airlines. Jurnal Ilman, 4(1), 33-46.

Cece. (2003). Analisis Hubungan Perencanaan Strategi Aliansi PDAM Tirtanadi-PT. Telekominikasi Divre I Terhadap Peningkatan Kualitas Pelayanan Pelanggan PDAM Tirtanadi... Universitas Sumatera Utara.

Dinamika, S. G. (2018). Gemstone Fever Hits Jakarta: A Lexical Meaning Analysis.

Dinamika, S. G., \& Sari, W. V. (2015). Applied Error Analysis of Comparative Degree Sentence Construction of Students in STIM Sukma Medan. Asian EFL Journal, 5, 112-119.

Dinamika, Soraya Grabiella (2014) THE EFFECT OF USING COLLABORATIVE STRATEGIC READING ON STUDENTS' ACHIEVEMENT IN READING NARRATIVE TEXT. Undergraduate thesis, UNIMED

Divisi Penelitian dan Pengembangan. (2012). Kupas Tuntas Adobe Flash Professional CS5. Yogyakarta: ANDI.

Fathimah, V. (2017). Pengaruh Perkembangan Jumlah Tabungan, Deposito dan Bagi Hasil terhadap Jumlah Pembiayaan yang Diberikan oleh Perbankan Syariah di Sumatera Utara. Jurnal Ilman, $5(1), 41-52$.

Hutahaean, J. (2014). Konsep Sistem Informasi. Yogyakarta: Deepublish.

Kadir, A. (2014). Pengenalan Sistem Informasi Edisi Revisi. Yogyakarta: Cv.ANDI OFFSET.

Lubis, D. I. D., \& Hidayat, R. (2017). Pengaruh Citra Merek dan Harga terhadap Keputusan Pembelian pada Sekolah Tinggi Ilmu Manajemen Sukma Medan. Jurnal Ilman, 5(1), 15-24.

Mainunah. (2012). Perancangan Company Profile Berbasis Video Sebagai Media Promosi SMK Muhammadiyah 1 Kepanjen. CCIT, 5 No 3, 284.

Nasution, W. A. (2009). Pengaruh kepuasan kerja karyawan terhadap intensi turnover pada call center Telkomsel di Medan. Jurnal Mandiri, 4(1), 1-11.

Nasution, W. A. (2013). Pengaruh kompensasi dan lingkungan kerja terhadap kepuasan kerja karyawan pada PT. Karya Deli Stelindo Medan. Jurnal Manajemen Bisnis STIE IBBI, 20(2), 177.

Nasutiona, L. K., Fahrurb, M., Christine, Imaduddind, \& Wardayani. (2017). The Calculation of Cost of Goods Sold "Gayo Arabica Coffee from Takengon" with Variable Costing Method. Journal Online Jaringan COT POLIPD (JOJAPS), 10, 82-87.

Ningratri, Y. A. (2017). Analisis Pengaruh Strategi Bauran Pemasaran Jasa (3P) terhadap Keputusan Mahasiswa Memilih STIM Sukma Medan. Riset \& Ejurnal Manajemen Informatika, 3(1), 50 56.

Nurlinda, \& Wardayani. (2014). Pengaruh Partisipasi Penyusunan Anggaran Dan Penggunaan Instrumen Manajemen Terhadap Kinerja Pengelolaan Dana Bantuan Global Fund Komponen Aids Pada Kementerian Kesehatan Ri. Jurnal Ilman, 1(1), 23-35.

Prana, R. R. (2016). Analisis Faktor-faktor yang Mempengaruhi Pendapatan Asli Daerah (PAD) Kota Tebing Tinggi. Jurnal Ilman, 4(1), 74-86. 
Purnomo, E. (2013). Perancangan Company Profile Sekolah Alam Minangkabau.

Raidani, Pertiwi, L. S., Wulandari, D. Y., \& Zuhri. (2016). Tobit and Interval Censored Regression Model. Global Journal of Pure and Applied Mathematics, 12(1), 981-994.

Rivai, Bambang, E., \& Danny, A. (2014). Pembangunan Sistem Informasi Pengolahan Data Nilai Siswa Berbasis Web Pada Sekolah Menengah Atas Kejururan(SMK) Miftahul Huda Ngadirojo. IJNS-Indonesian Journal On Networking And Security, 3(2), 19-25.

Rusman. (2012). Model-Model Pembelajaran. Depok: PT. Rajagrafindo Persada.

Sabdillah, R., Hidayat, R., Lubis, D. S. W., \& Wardayani. (2017). Influence of Celebrity Endorser Raisa Andriana in Advertisement on Magnum Ice Cream Brand Image on the Transmart Costumers. Journal Online Jaringan Pengajian Seni Bina (JOJAPS), 10, 112-115.

Safriandi, F., Pertiwi, L. S., Fitriani, A., \& Zuhri. (2016). Truncated Regression Model and Nonparametric Estimation for Gifted and Talented Education Program. Global Journal of Pure and Applied Mathematics, 12(1), 995-1002.

Sinaga, S., Pertiwi, L. S., Ardian, T., \& Zuhri. (2016). Inventory Simulation Optimization Under Non Stationary Demand. International Journal of Applied Engineering Research, 11(1), 524-529.

Sinuhaji, E. (2010). PENERAPAN LAYANAN UNGGUL DALAM PEMASARAN PRODUK BANK. Jurnal Mediasi, 2(1).

Sinuhaji, E. (2013). PENGARUH BUDAYA ORGANISASI TERHADAP KEPUASAN KERJA KARYAWAN PADA JASA PERHOTELAN (Studi Kasus di Garuda Plaza Hotel Medan). Bisnis Administrasi, 2(1), 2537.

Sinuhaji, E. (2014). Pengaruh Kepribadian, Kemampuan Kerja dan Motivasi Kerja terhadap Kinerja SDM Outsourcing pada PT. Catur Karya Sentosa Medan. Jurnal Ilman, 1(1), 11-22.

Subhan, M. (2012). Analisa Perancangan Sistem. Jakarta: Lentera Ilmu Cendekia.

Sugiyono. (2012). Metode Penelitian Bisnis (Pendekatan kuantitatif,Kualitatif dan R\&D). Bandung: Alfabeta.

Sukendro, H. A. (2012). Pengaruh Citra Merek dan Kualitas Pelayanan terhadap Kepuasan Jama'ah pada Kelompok Bimbingan Ibadah Haji (KBIH) Indosat Medan. Universitas Terbuka.

Sunarya. (2012). Perancangan Media Company Profile Sebagai Penunjang Pencitraan dan Program Promosi Pada SMK Kesehatan Bina Insan Cendikia Tangerang. CCIT, 45.

Susanto, A. (2013). Sisteam Informasi Akuntansi. Bandung: Lingga Jaya.

Sutabri, T. (2012). Konsep Dasar Sistem Informasi. Yogyakarta: Cv.ANDI OFFSET.

Syafii, \& Handayani, H. (2016). Pengolahan Data Nilai Siswa Berbasis Web Pada SMK Muhammadiyah Karang Anyar. ISSN:2477-3042, 2(1).

Wahyuni, D. S., \& Wardayani. (2016). Analisis Return on Asset, Current Ratio dan Debt Ratio dalam Menilai Kinerja Keuangan pada PT . Pelabuhan Indonesia I (Persero) cabang Belawan. Jurnal Ilman, 4(1), 59-73.

Wardani, S. (2013). Sistem Pengolahan Data Nilai Siswa Berbasis Web Pada Sekolah Menengah Atas (SMA) Muhammadiyah Pacitan. IJNS-Indonesian Journal On Networking and Security, 2. 
Widjanarko, B. (2015). PENGARUH PEMERIAN KOMPENSASI DAN KOMUNIKASI TERHADAP SEMANGAT KERJA KARYAWAN PADA BUMI KARYA TAMA INSURANCE CABANG MEDAN. Jurnal Research Sains, 1(2), 130-152.

Winata, E. (2016). Pengaruh Kepuasan Kerja dan Kompensasi terhadap Kinerja Karyawan pada Hotel Inna Dharma Deli Medan. Jurnal Ilman, 4(1), 1-17.

Winata, E. (2016). PENGARUH KOMPENSASI DAN KOMUNIKASI TERHADAP SEMANGAT KERJA KARYAWAN PADA PT. FIF CABANG MEDAN. Jurnal Dunia Ilmu, 2(1), 17-31.

Winata, E. (2017). PENGARUH BAURAN PEMASARAN JASA TERHADAP LOYALITAS KONSUMEN PADA GRAND SERELA HOTEL \& CONVENTION MEDAN. Jurnal Mutiara Manajemen, 1(1), 109-121.

Yakub. (2012). Pengantar Sistem Informasi. Yogyakarta: Graha Ilmu.

Yulianna, R. (2013). Pembuatan Video Profile Sekolah Menengah Atas 2 Surakarta.

Yuze, Y. C., Priyadi, Y., \& Candiwan. (2016). Analisis Sistem Manajemen Keamanan Informasi Serta Rekomendasi Model Sistem Menggunakan Data Flow Diagram Pada Direktorat Sistem Informasi Perguruan Tinggi. Jurnal Sistem Informasi Bisnis, 1, 38-45. 